\title{
The social construction of caves and rockshelters: Chauvet Cave (France) and Nawarla Gabarnmang (Australia)
}

Jean-Jacques Delannoy ${ }^{1}$, Bruno David ${ }^{2}$, Jean-Michel Geneste ${ }^{3}$, Margaret Katherine ${ }^{4}$, Bryce Barker ${ }^{5}$, Ray L. Whear ${ }^{4} \&$ Robert G. Gunn ${ }^{6}$

Caves and rockshelters are a key component of the archaeological record but are often regarded as natural places conveniently exploited by human communities. Archaeomorphological study shows however that they are not inert spaces but have frequently been modified by human action, sometimes in ways that imply a strong symbolic significance. In this paper the concept of 'aménagement', the re-shaping of a material space or of elements within it, is applied to Chauvet Cave in France and Nawarla Gabarnmang rockshelter in Australia. Deep within Chauvet Cave, fallen blocks were moved into position to augment the natural structure known as The Cactus, while at Nawarla Gabarnmang, blocks were removed from the ceiling and supporting pillars removed and discarded down the talus slope. These are hence not 'natural' places, but modified and socially constructed.

Keywords: Chauvet Cave, Nawarla Gabarnmang, rockshelter, archaeomorphology, aménagement, geomorphological mapping, rock art

\section{Introduction}

It is commonplace in archaeology to make reference to—and systematically investigate-site formation processes both natural and cultural (for a classic exposition, see Schiffer 1976). Among these investigations, it is not unusual, although less common, to focus attention on the way that a site's natural layout affected human activities — or how people made use of natural configurations in their daily lives. Examples include how geology and landform affect where people decide to live (e.g. Heydari 2007); the tendency for people to clean rockshelter floors by creating 'dump zones' toward the rear wall (e.g. Burns 2005); and the propensity

1 Laboratoire EDYTEM, Université de Savoie, F-73376 Le Bourget du Lac cedex, France (Email: jean-jacques.delannoy@univ-savoie.fr)

2 Programme for Australian Indigenous Archaeology, School of Geography and Environmental Science, Monash University, Clayton, Victoria 3800, Australia (Email: bruno.david@monash.edu)

3 Centre National de Préhistoire, Ministère de la Culture et de la Communication, UMR PACEA, Université de Bordeaux 1, 24000 Périgueux, France (Email: jean-michel.geneste@culture.gouv.fr)

4 Jawoyn Association Aboriginal Corporation, Pandanus Plaza, First Street, PO Box 371, Katherine, Northern Territory 0851, Australia (Email: ray.whear@jawoyn.org)

5 School of Humanities and Communication, Public Memory Centre, University of Southern Queensland, Toowoomba, Queensland 4350,Australia (Email: bryce.barker@usq.edu.au)

6329 Mt Dryden Road, Lake Lonsdale, Victoria 3381, Australia (Email: gunnb@activ8.net.au) 
for bedrock surfaces and ceilings to weather and exfoliate as a result of human habitation, especially firing practices (e.g. Hughes 1977). The ceiling height of rockshelters affects the movement of people and the layout of activity areas (e.g. Theunissen et al. 1998). Geology also influences the positioning of particular artistic designs, and the forms they take, as most famously exemplified by the spotted horse of Pech-Merle in France (e.g. Lorblanchet 2010). The natural layout of caves also structures social activities as these relate to various levels of liminality and sacredness, such as the painting of the most dangerous faunal taxa, and humans and other special anthropomorphic beings in the deepest and least accessible parts of French Upper Palaeolithic caves (e.g. Leroi-Gourhan 1965).

However, while caves and rockshelters may be recognised as negotiated spaces, they are rarely, if ever, treated as constructed architecture. This is despite a rich literature on dwelling and inhabitation perspectives in the social construction of the landscape (e.g. Ingold 1993; Thomas 2008) and the phenomenology of place (e.g. Tilley 1994). While such approaches to the archaeology of place have been the subject of a burgeoning literature on social interpretations of open landscapes and landscape features (e.g. Van Dyke 2008), they have not had major impacts on archaeological investigations of caves and rockshelters (for classic views of the social construction of place, see Tuan 1977 and Casey 1993).

\section{Aménagement}

Archaeological research often brings together varied specialist fields. One such collaborating discipline is geomorphology, whose objective is to shed light on the processes that caused sediments to be where they are today. The use of specialised geomorphological mapping techniques, such as have been used for the study of rock art (e.g. Delannoy et al. 2001, 2004), offers the researcher an opportunity to think of the materiality of a site in a way that connects its different components via the notion of aménagement.

Taken from the French, aménagement concerns how people are actively engaged in the construction of a given place through dwelling and inhabitation (see Ingold 2000 for discussion of 'dwelling'; Thomas 2008 for 'inhabitation'). The rock walls and the open spaces within caves and rockshelters are included in a site's social fabric by the way people engage with them. Here aménagement is more than 'management' or 'refurbishment', for, unlike these latter concepts, it foregrounds the active social configuration of place as construction. Aménagement creates the place that is lived and engaged with, rather than simply improving a pre-existing place. In this context, rock art participates in such a process of construction and site formation, not through a transformation of natural rock into a culturally transformed canvas, but rather through a fluid engagement with space as an already meaningful realm that is liveable, owned, usable or otherwise transformable in a process of ongoing construction and 'house-keeping', a process at the core of aménagement.

The concept of aménagement, with its emphasis on social construction in the course of inhabitation, is particularly apt for exploring the history of sites in cross-cultural perspective, especially in Australia. Throughout Aboriginal Australia, locales are understood to have formed as the ancestors metamorphosed into place at the beginning of time, giving place to the present. In this Australian Aboriginal formulation, place is socially created from the outset, rather than being simply a 'natural' topography subsequently adjusted by descendent 
generations. Our approach has a similar nuance, albeit different cosmological or ontological foundation. By considering the individual material features of a cave or rockshelter as the embodiment of past social engagements, we gain access to its historical shaping. In many ways this is what geomorphologists already do, the difference being a dwelling perspective informed by practices of aménagement.

Such a perspective enchains aménagement with two other separate but mutually informed concepts, 'social geomorphology' and 'archaeomorphology'. While aménagement is a socio-environmental process, social geomorphology investigates social engagements with the environment through the study of sediments. Archaeomorphology treats sediments themselves as part of that archaeology, rather than as part of an essentially natural geomorphological record.

Our major research tool is a detailed form of geomorphological mapping (Joly 1977; Delannoy et al. 2001, 2004). This allows the graphic representation of a range of threedimensional features (e.g. floor, walls, ceiling, roof) by showing processes of formation through time using colour coding (see below for examples). A broad range of site features and processes can be shown in fine detail, to the point, for example, of matching every rock now found on a site's surface to its original position and determining how they have been moved (Delannoy et al. 2001). Such mapping allows us to distinguish a range of site formation processes and human actions not evident from standard archaeological or geomorphological methods.

By using the full gamut of geomorphological and archaeological techniques, the archaeomorphological study of a site thus aims to determine: 1) where people moved items across space (e.g. by mapping where objects such as rock slabs lie, and matching them to their original locations); 2) when specific engagements with a place's materiality took place (by dating the creation and movement of such objects); and 3) how people have shaped immovable aspects at a given location (e.g. by documenting how objects have been broken up or otherwise modified). The ultimate aim is to understand the particular culture of material engagement through time, as a step towards understanding how people engaged with their lived worlds more generally.

\section{Chauvet Cave}

The discovery of Chauvet Cave in 1995 (Figure 1) had a powerful impact on the international archaeological community, quickly bringing together archaeologists, rock art experts, palaeontologists, geologists and geomorphologists (cf. Clottes 2001). The geomorphological study of the site has had three major aims: 1) to reconstruct the morphology of the cave at the time of human occupation; 2) to determine when the prehistoric entrance was sealed, and the associated environmental conditions; and 3) to understand the evolution of the cave since its closure.

The dating of these events has relied on speleothems and archaeological evidence (e.g. Valladas \& Clottes 2003; Genty et al. 2004). The three aims led the Chauvet Cave research team to adapt standard geomorphological mapping techniques so as to take into account the 'natural' and 'cultural' objects found on the cave floor (Delannoy et al. 2001, 2004). Mapping enabled the processes responsible for the presence of objects on the ground to be (C) Antiquity Publications Ltd. 
identified and their relative or absolute chronology to be determined. By doing this, the morphology of the cave at different points in time could be reconstructed, and the way that palaeontological and archaeological objects reached their present locations understood.

The systematic mapping of objects lying

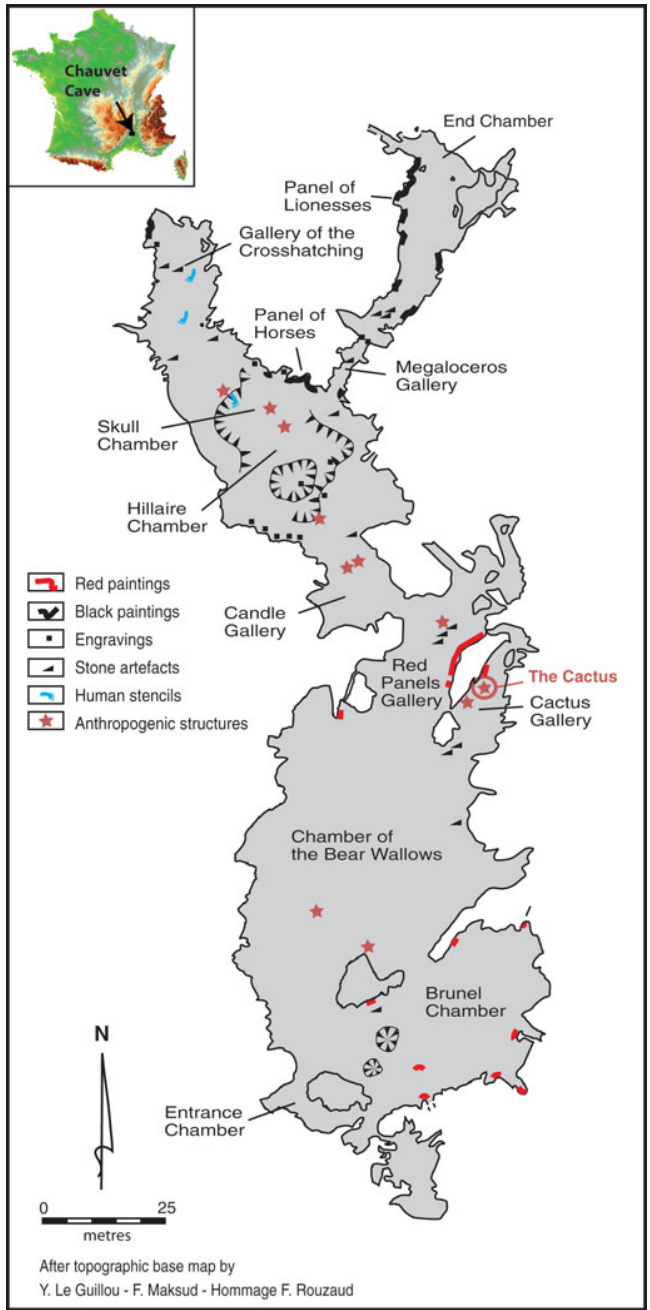

Figure 1. Map of Chauvet Cave. on the cave floor has highlighted the presence of structures including bones, piles and alignments of rocks. The best known and most obvious of these is the bear skull resting on a large block of stone in Skull Chamber (Figure 2). Here a cave bear (Ursus spelaeus) skull was found with charcoal on its outer surface. Three statistically similar radiocarbon determinations of $32360 \pm 490 \mathrm{BP}, 31390 \pm 420 \mathrm{BP}$ and $32600 \pm 490$ BP were obtained from the charcoal. The skull was intentionally placed on a prominent limestone block and is part of a complex configuration that includes dozens of other cave bear skulls nearby. This is a monumental structure incorporating the decorated walls, generations of charcoal drawings, figurative faunal representations and abstract engravings.

The identification of such structures has led archaeologists and geomorphologists to ask how and why they came to be formed. To what degree are they the result of processes such as roof-fall, natural death and the movement of archaeological and palaeontological objects by elemental forces, and to what degree are they the result of intentional human actions? Our archaeomorphological approach to Chauvet Cave has aimed to define the origins of each structure, and to determine the degree to which people were involved in their formation. This ongoing work began in Cactus Gallery which has several such structures, the most important being the one that surrounds the speleothem known as The Cactus (Figure 3).

\section{Geomorphology of The Cactus}

The Cactus consists of a ring of limestone blocks with a central ensemble of Holocene stalagmites. In the early years of research at Chauvet Cave, we were often asked about

(C) Antiquity Publications Ltd. 


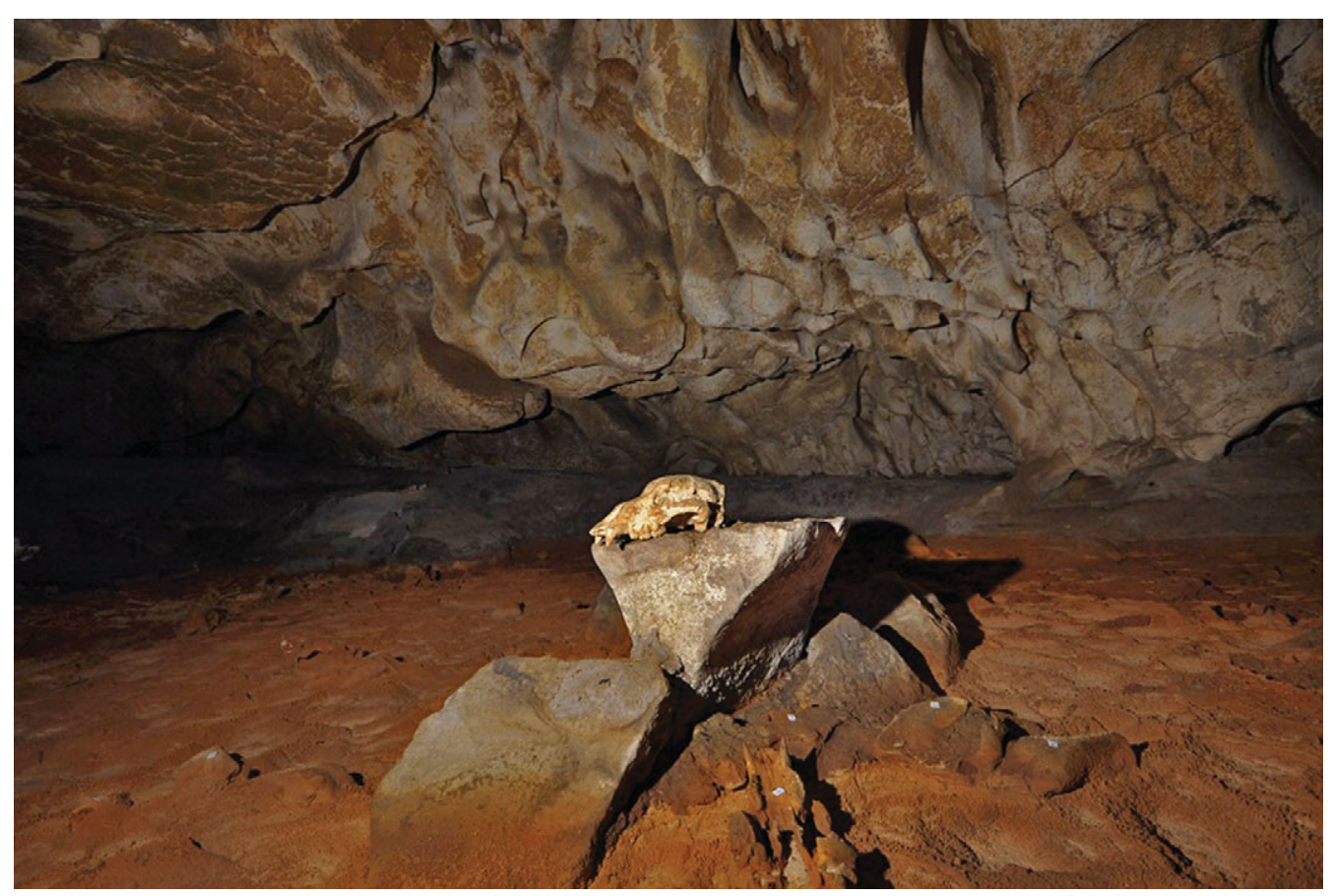

Figure 2. Cave bear skull in Skull Chamber, Chauvet Cave (C)Jean-Michel Geneste).

the status of this structure, some seeing it as a cultural construct built around pre-existing stalagmites (Figure 3), others attributing the entire complex to natural stalagmitic growth and block collapse. To resolve the question of its origins, we sought to determine the status of each component by investigating its morphogenesis at high spatial resolution.

The Cactus consists of 10 large rock slabs encircling a group of stalagmites, with several upright stones located on the outer rim of the main structure (Figures 3 and 4). A detailed mapping of their geometry and their original nesting space on the ceiling above enabled us to reconstruct the origins and age of the individual pieces and of the structure as a whole (Figures 4 and 5; see Delannoy et al. 2004; 2012 for further details of these investigations). Three key phases have thus been identified in the formation of The Cactus:

1) Petrographic analysis shows that blocks $D$ and $E$ on Figures 4 and 5 are derived from a perched false floor that collapsed following the erosion of its supporting sediments.

2) This was followed by the collapse of a hanging vault (A and B on Figure 5) that, in falling, struck a large pre-existing stalagmite (Phase 2 on Figure 5). The stalagmite shattered into several large fragments ( $\mathrm{C}$ and $\mathrm{C}^{\prime}$ on Figure 4$)$ and the ceiling vault broke into a number of pieces on impact (A and A', B and B"). Large pieces of the stalagmite also landed on slabs of the collapsed false floor (of Phase 1, D and E) at ground level, re-orienting them into sub-vertical positions ( $\mathrm{D}$ and $\mathrm{D}$ '). The period of time between these two roof-fall events (Phase 1 and Phase 2) cannot currently be estimated, but we know that The Cactus already existed at the time of the second human occupation of Chauvet Cave c. 26000 BP. Indeed, (C) Antiquity Publications Ltd. 


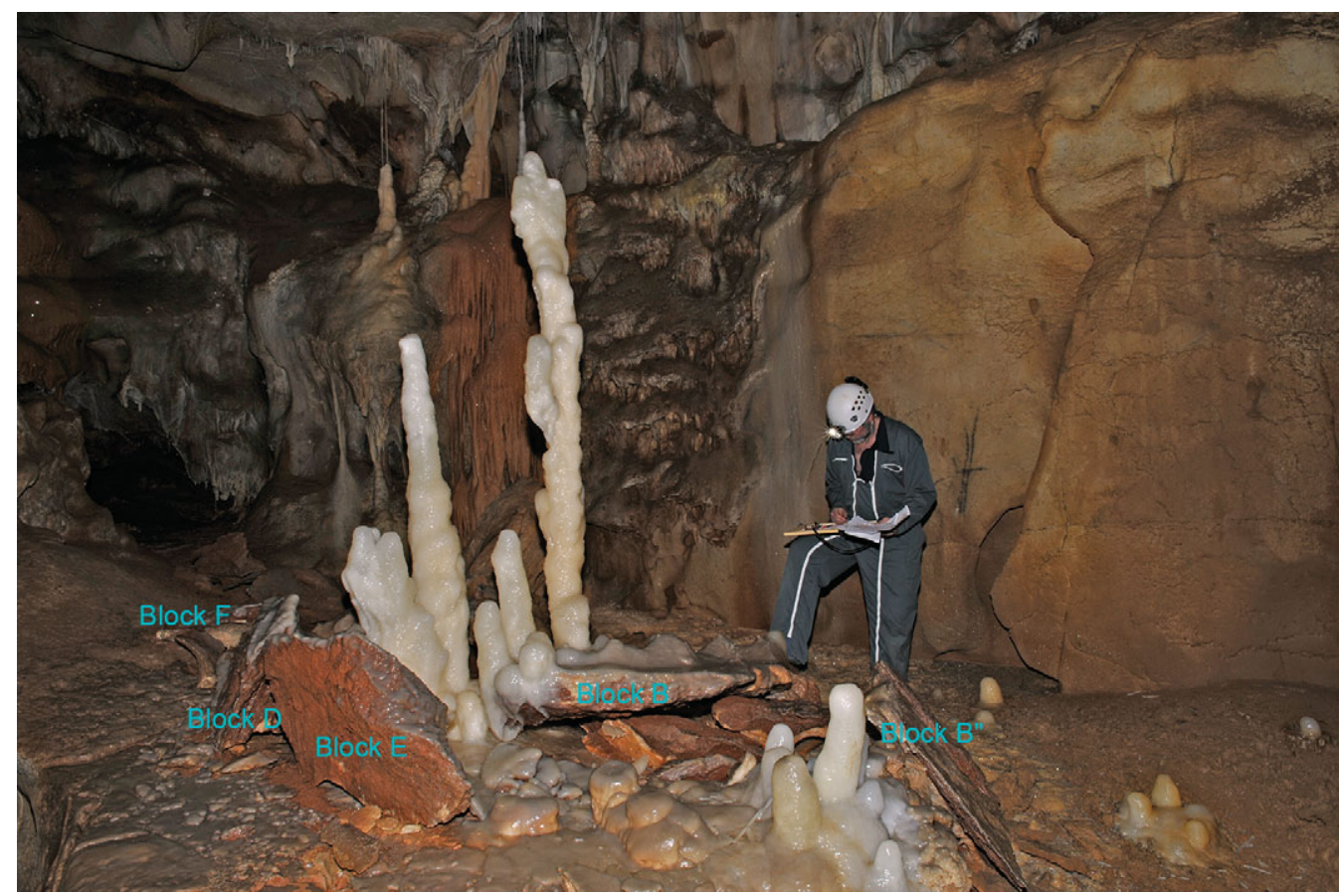

Figure 3. The Cactus, Chauvet Cave. Block codes correspond with those on Figures 4 and 5 (C) Stéphane Jaillet).

a flint tool was found within a cavity in block $\mathrm{A}$, where it was intentionally placed. Charcoal and torch smoke staining occur on that block.

3) We might infer a natural cause for the entire structure, but detailed analysis of blocks B' and F reveals anthropogenic modifications. Block B" was intentionally moved, raised and secured in place by human action to extend the semi-concentric layout generated by the collapse of the ceiling. Block $\mathrm{F}$ was moved, placed on slab D and rigged by a small block to hold it in its raised position. This human intervention signals a cultural dimension for The Cactus as a whole. We may wonder about the place of the stalagmite concretions at the heart of the structure: were they already present prior to the anthropogenic redevelopment of the blocks? The fact that block B" was propped against a concretion about $100 \mathrm{~mm}$ in height suggests that the latter, although modest in size, was already present. However, the bulk of the stalagmite from which the concretion originated, i.e. the stalagmite at the heart of The Cactus, dates to the Holocene and is thus later in age than the aménagement of the ensemble. This point is critical because at first glance the current subterranean landscape suggests that this Pleistocene structure formed around the stalagmites at the centre of The Cactus. In reality, however, the latter includes an original central Pleistocene stalagmite that predates the surrounding blocks, and later Holocene stalagmites.

Detailed archaeomorphological analysis of The Cactus has brought to the fore the role of people in redesigning (by removal of two slabs) and engaging with internal spaces at Chauvet Cave, even though the bulk of The Cactus is of natural origin, rather than made

(C) Antiquity Publications Ltd. 


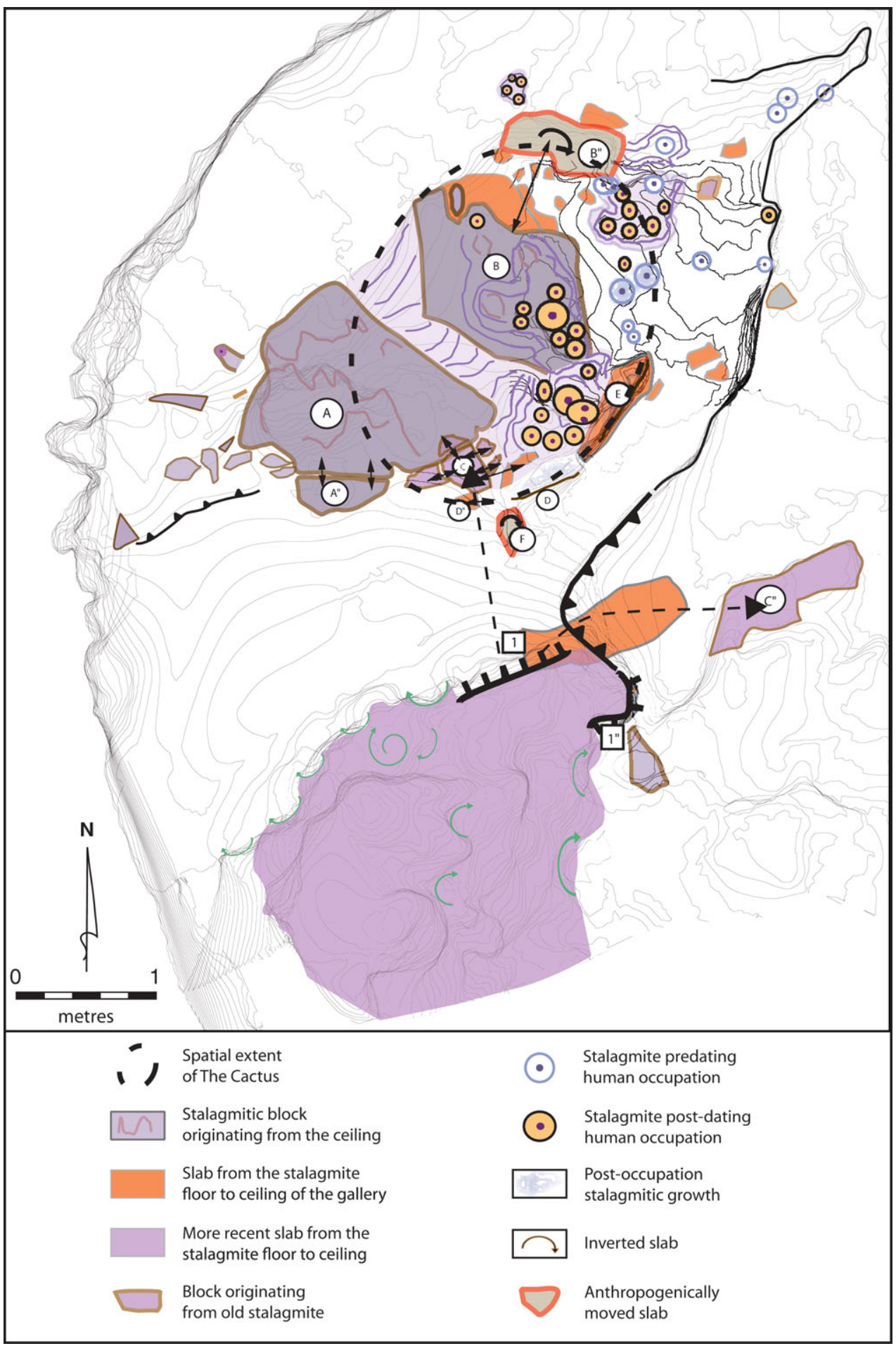

Figure 4. Geomorphological map of Cactus Gallery, Chauvet Cave.

(C) Antiquity Publications Ltd. 


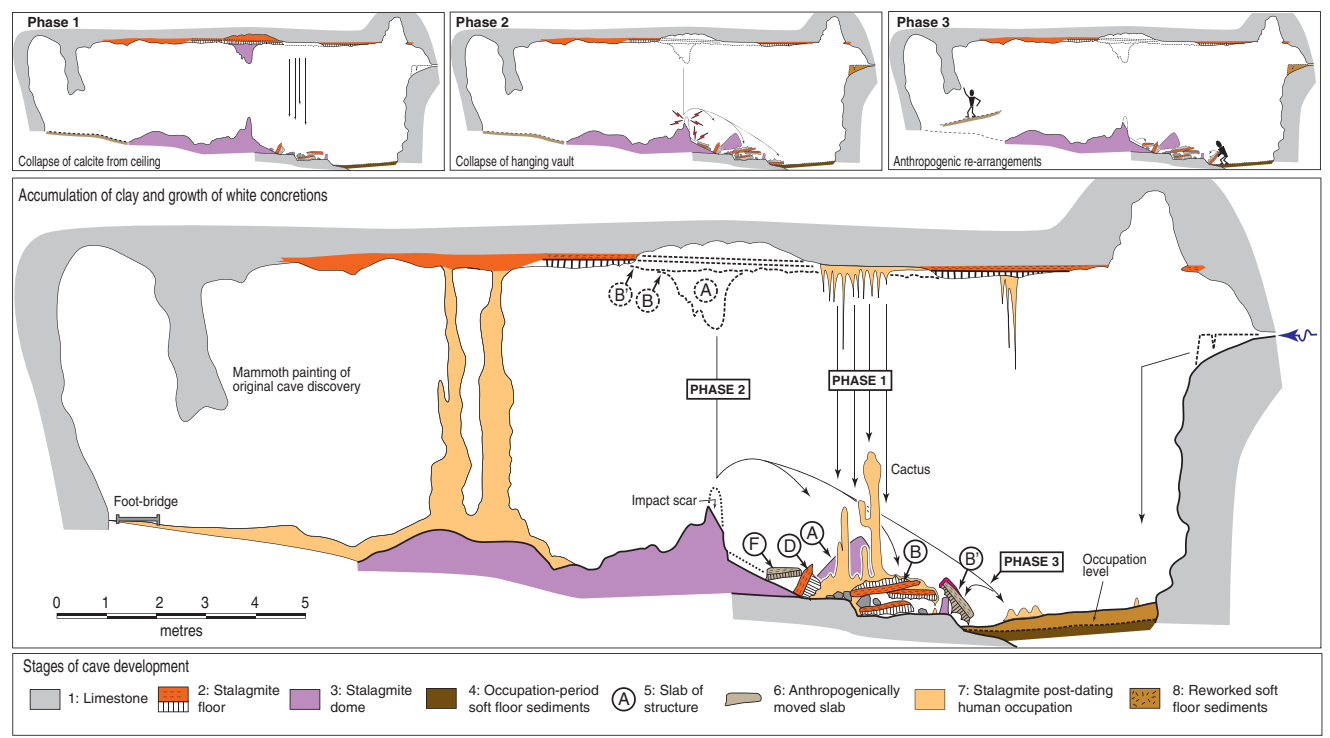

Figure 5. Schematic representation of morphogenic phases for The Cactus.

by people. The demonstration that people have modified this particular structure in minor ways nonetheless gives the entire product a cultural status whose significance remains to be determined. At the same time it highlights the fact that engagement with space is mediated through meaning, indicating that an understanding of human engagements at Chauvet Cave needs to consider more than the rock art and other obvious traces of human creativity. It is useful to ask why The Cactus was created in this side gallery. Why was a geographical dead-end 'decorated' in this way? There are other human-made structures in this chamber, including limestone slabs arranged in small alcoves and finger imprints in clay fill. Should we link The Cactus to nearby cave paintings, or to the upper conduit that provides access to the Red Panels Gallery, where another stone structure can be found? Our ability to determine how The Cactus was formed, via archaeomorphological mapping of the kind expounded in this paper, raises new issues and anthropological questions. Such mapping enables us to highlight human interventions within the cave, guide new avenues of enquiry, and thus better understand the spatial distribution of social acts and cultural engagements.

\section{Nawarla Gabarnmang}

Nawarla Gabarnmang is one of thousands of rock art sites in Jawoyn country, northern Australia. This double-ended rockshelter contains impressive rock art panels covering large areas of the ceiling (Figure 6). From the outset, archaeological and geomorphological research aimed to understand the site's physical configuration in temporal and cultural context. In particular, archaeomorphological mapping enabled us to highlight links between the rock art and rock formations, the timing and nature of occupation and its relationship to the

(C) Antiquity Publications Ltd. 


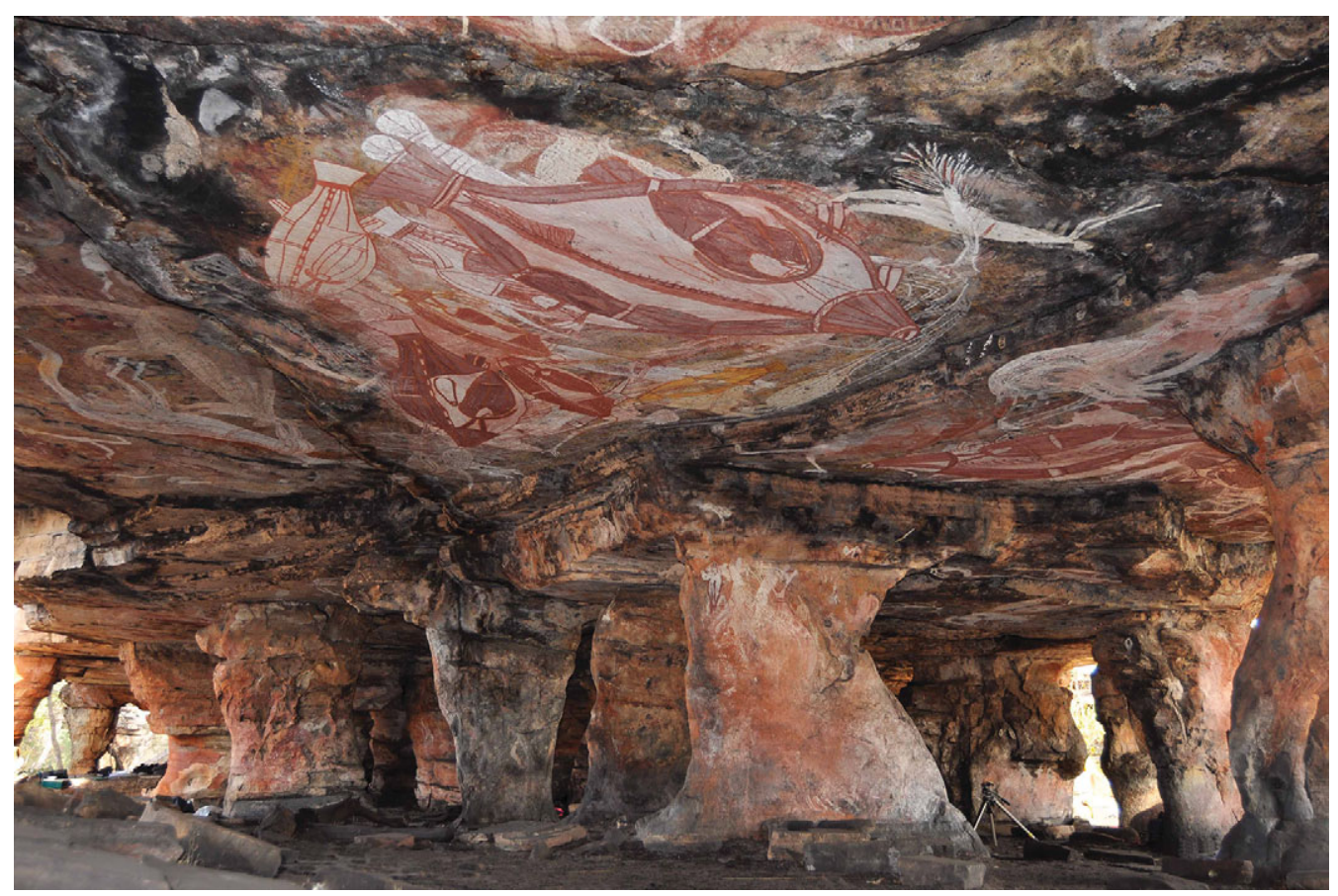

Figure 6. Nawarla Gabarnmang (C) Jean-Jacques Delannoy and the Jawoyn Association).

developing cave structure, and the nature of aménagement during the different phases of occupation (Figures 7 and 8).

Nawarla Gabarnmang comprises a gridded network of pillars supporting a thick, multilayered sandstone and quartzite ceiling. The present configuration of remnant pillars and ceiling layers represents an anthropic cave structure.

Nawarla Gabarnmang consists of Proterozoic Marlgowa Sandstone of the Kombolgie formation (Carson et al. 1999), characterised by $0.1-0.4 \mathrm{~m}$-thick cross-beds. Although poorly soluble, these compact, quartz-rich sandstones and quartzites have been the seat of powerful chemical alterations acting upon layer planes and fissures. Geologically slow dissolution of the bedrock has resulted in a hollowing out or 'phantomisation' of the rock (Quinif 2010), a particular cave-forming process causing the regular grid-shaped structure of underground cavities and pillars (Figure 6).

Of particular interest at Nawarla Gabarnmang are the voids between the pillars (typically c. $1 \mathrm{~m} \times 2 \mathrm{~m}$ apart in the south-west corner of the site, and more than $8 \mathrm{~m}$ apart in the central-east portion). The large, flat ceiling with sub-horizontal sandstone slabs, supported by some 20 sparsely distributed pillars, seems to defy the laws of gravity. The floor of the sheltered area, generally flat and sub-horizontal, is ashy sand with scattered blocks. Within the fill are rich archaeological deposits including stone artefacts and animal bones, as revealed through excavation (David et al. 2011; Geneste et al. 2012). Here human occupation goes back more than 45000 years.

(C) Antiquity Publications Ltd. 


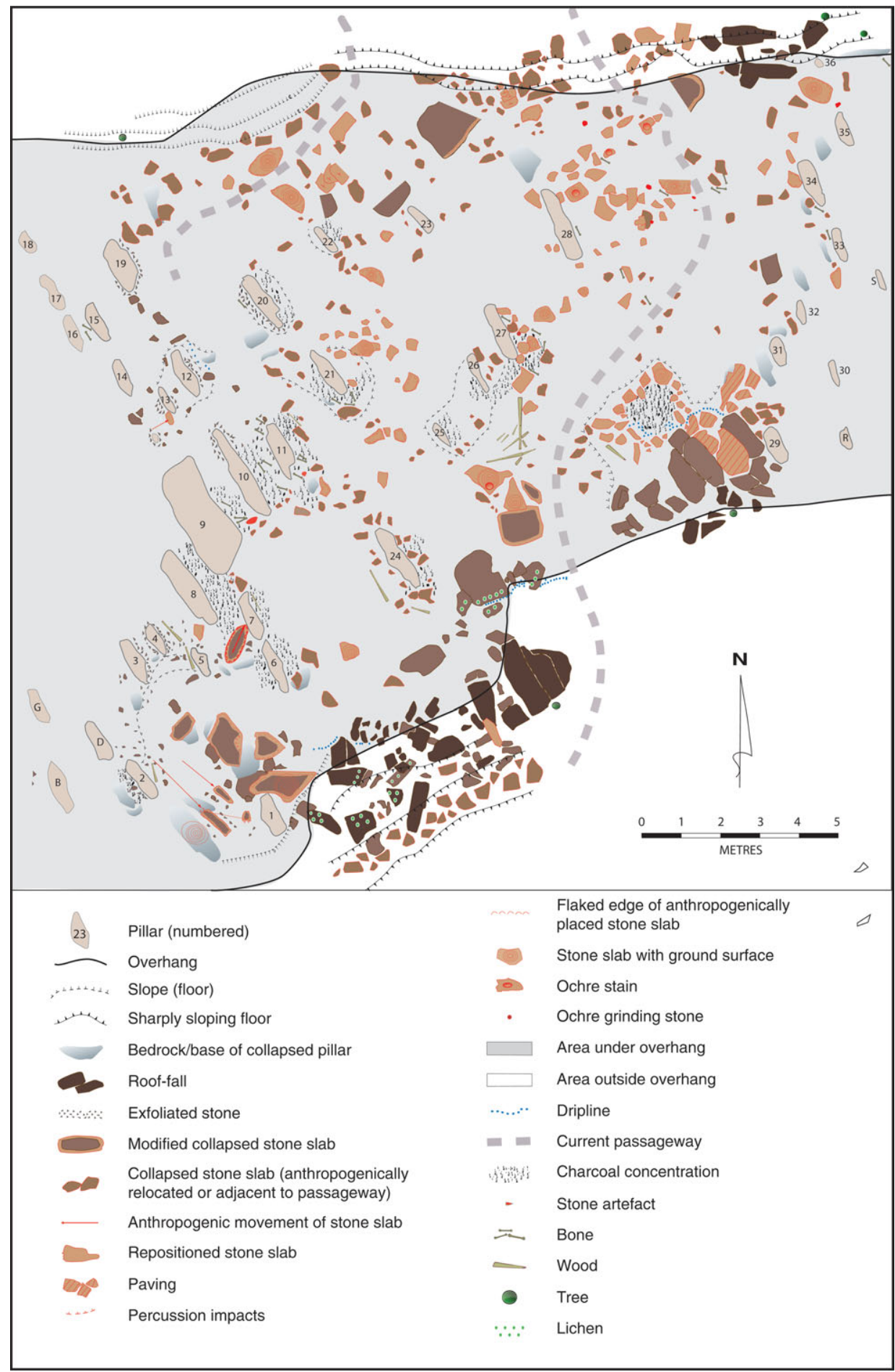

Figure 7. Archaeomorphological map of the floor of Nawarla Gabarnmang.

(C) Antiquity Publications Ltd. 


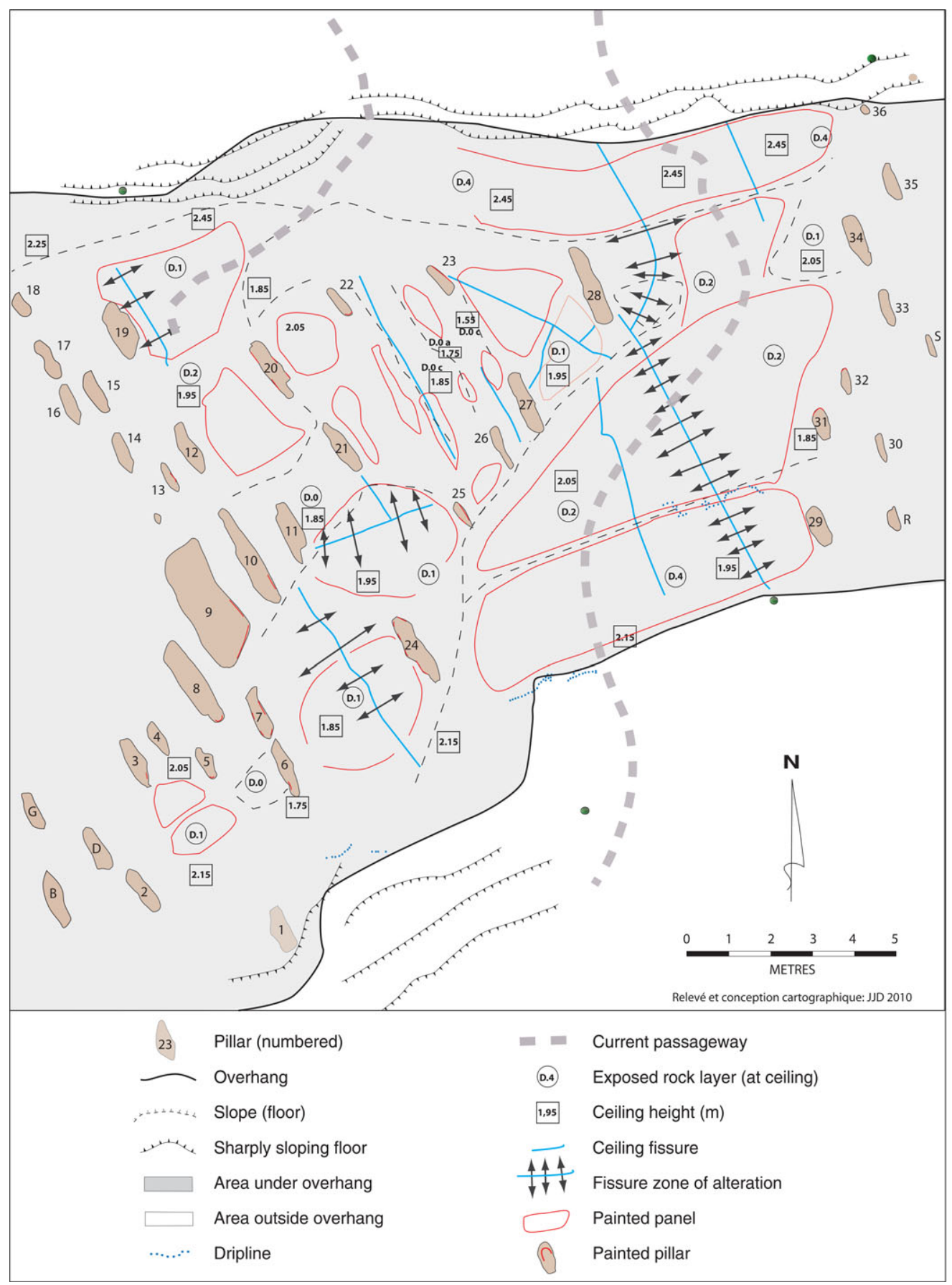

Figure 8. Archaeomorphological map of the ceiling of Nawarla Gabarnmang.

(C) Antiquity Publications Ltd. 


\section{Aménagement at Nawarla Gabarnmang}

The first question we asked of Narwarla Gabarnmang was this: is it a natural geological feature with a unique morphology, or has the site been shaped by people over time? The answer depends upon an understanding of the origins of the voids between the pillars. Apart from the original voids created by the dissolution of the rock over long geological periods of time, the space between many of the pillars has been created by the disappearance of older pillars and the successive collapse of ceiling slabs. However, presenting a challenge to understanding the disappearance of the older pillars is the paucity of blocks at floor level. The latter cannot account for the sum of the missing pillars and roof-fall. Some of the collapsed material is probably buried below the soft deposits, but their shallowness (typically $0.7-0.8 \mathrm{~m}$ in depth) and the flatness of the floor indicate that another explanation is required. These observations led us to pay extra attention to the few slabs present on the ground surface.

The space between pillars $1-8$ to the south-west of the painted ceiling is particularly instructive. This space has several blocks on the ground that originally came from the ceiling (Figure 9) and former pillars. The morphological study of the blocks originating from the ceiling indicates that the largest have been reduced by flaking around their edges. Furthermore, the human treatment of individual collapsed blocks has not always been the same. Blocks coming from particularly resistant layers of quartzitic sandstone were harvested for the manufacture of flaked stone artefacts. The numerous stone artefacts evidencing all stages of reduction present on the surface and in the excavations indicate that the manufacture of stone tools from this local raw material was conducted entirely on-site. The blocks that did not have any, or any further, role to play in the production of stone tools were broken-up and those that were too large to move had their edges trimmed, arguably to enable people to move more freely across the rockshelter. These large blocks are typically now oblong in shape with blunt edges. They often have ground surfaces, indicating that they were also used to grind ochre, stone artefacts or other materials.

Smaller collapsed blocks originating from the ceiling or former pillars were fragmented on-site by percussion, with large fragments individually removed to outer parts of the site, thereby opening up the space between the remaining pillars (Figures 9 and 10). These blocks, individually reduced in size by human action, have been moved towards the talus slope bordering both the north and south sides of the shelter. Lithostratigraphic analyses of the blocks on these talus slopes enabled us to match individual rocks with remnant ceiling layers (typically by comparing block and bedrock layer thickness, grain size and mineralogy), and indicate that the talus slabs each came from a particular ceiling layer. The accumulated blocks, consisting of slabs each measuring decimetres in thickness and prograding across the front of the shelter, cannot be confused with natural overhang collapse. The talus is itself an anthropogenic structure. Here the rock slabs accumulated gradually as layers of rock were removed from the ceiling and pillars collapsed following the removal of the ceiling above them (Figure 11). The result is a thinner ceiling consisting of fewer rock layers perched over more widely spaced remnant pillars. The cave itself was fashioned by people in the course of stone quarrying, clearance of collapsed blocks, and in the general aménagement of the living space.

(C) Antiquity Publications Ltd. 


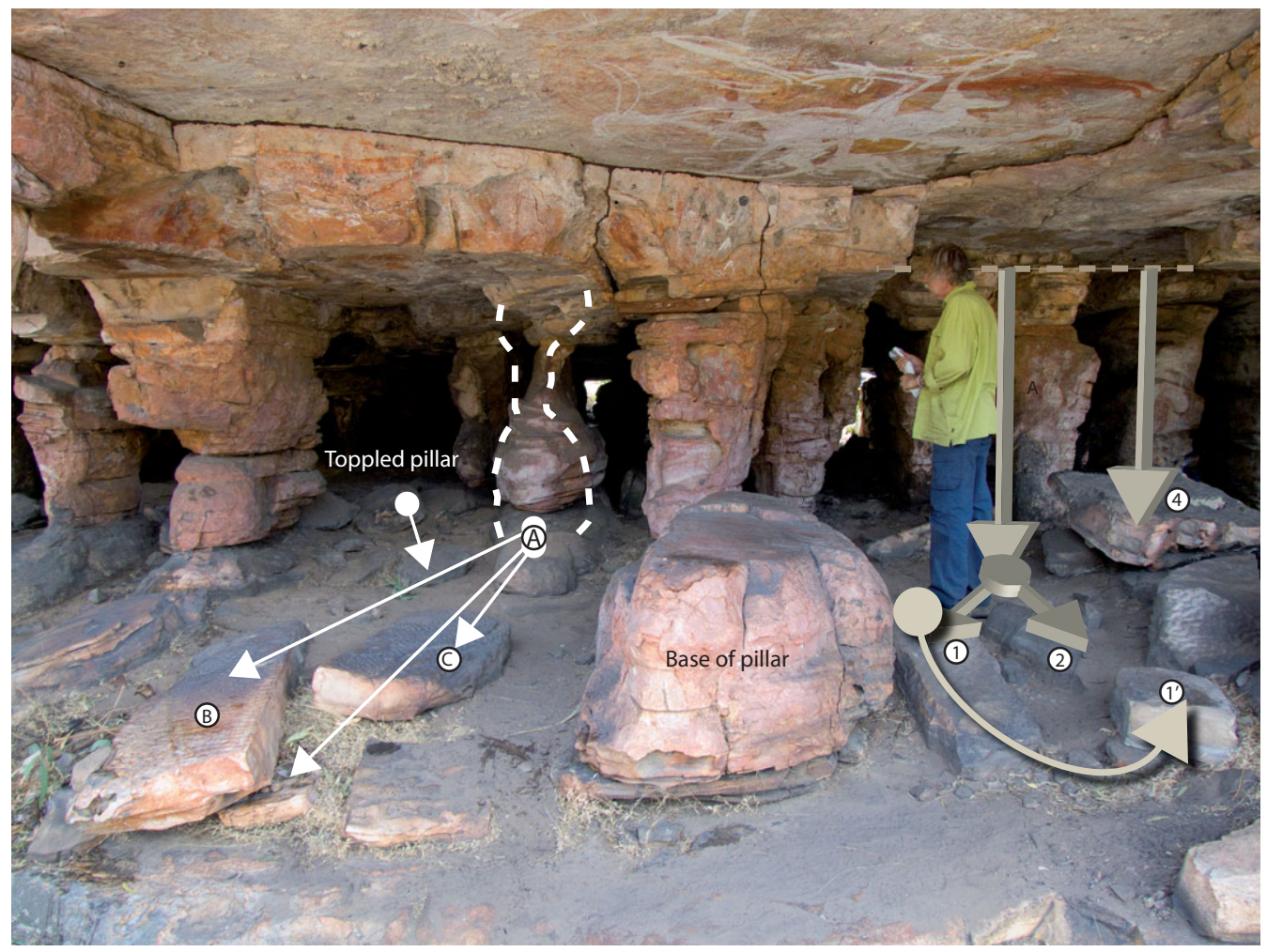

Figure 9. Removed blocks in the south-west sector of Nawarla Gabarnmang. Some individual blocks (e.g. 1 and 1') have been conjoined; in other cases they have been matched to their original positions by refitting in three-dimensional space, using grain size and mineralogy as further corroborating evidence (e.g. A, B and C). This south-west section of the site, one of the last to have been worked, contains a number of sandstone blocks in the process of being removed from the cave. The codes shown on this figure correspond to those on Figure 10.

The extraction of slabs from the ceiling and from former pillars, followed by their discard on the talus slope, involved an intentional aménagement of the site. This may have been done to achieve both an increased sheltered space and an unobstructed floor. It is worth asking how this opening up of the internal space relates to what people subsequently did to the ceiling. Archaeomorphological mapping points to another dimension of the site's development: by removing large slabs from the ceiling, new, flat surfaces were created. Was this an attempt to expose the most appropriate rock strata for painting? Were old panels removed to produce new panels for new works? Were new, large surfaces created in order to allow ongoing artistic endeavours, each related to the previous in an interconnected artistic and cosmological logic? Or was the aim to destabilise the supporting pillars solely to generate a wider living space? Did people simply want to access certain ceiling strata as raw material for the manufacture of stone tools? Whatever the cause(s), the ceiling and floor of the site were each subject to intentional adjustments resulting in a chain of actions: pillars were toppled; ceiling slabs were caused to fall; collapsed slabs were broken into smaller pieces of regular dimensions, typically about $0.4 \mathrm{~m} \times 0.4 \mathrm{~m}$ in size; slabs were flaked for the production of tools; some blocks were used for grinding; large blocks were fragmented into (C) Antiquity Publications Ltd. 


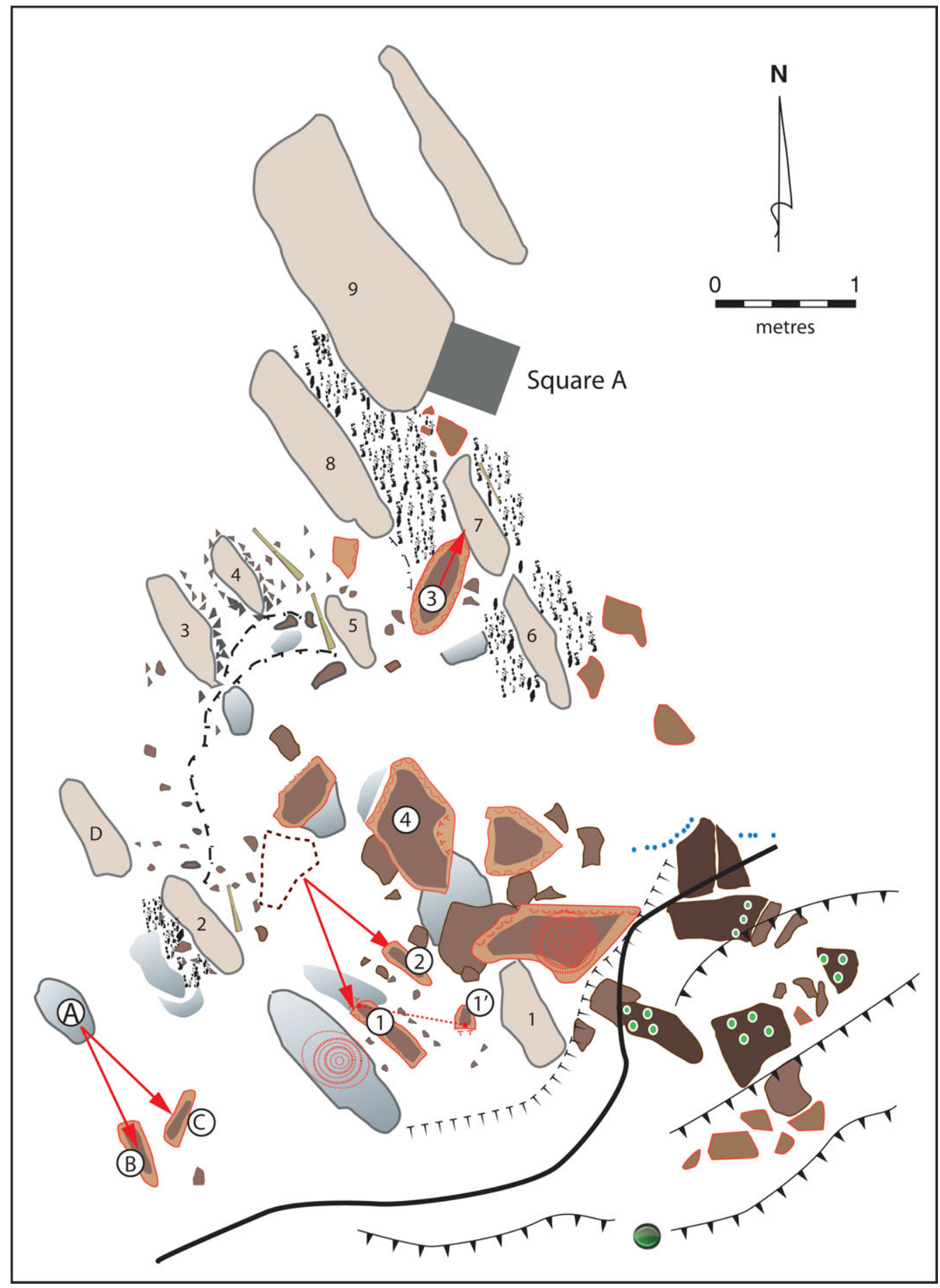

Figure 10. Schematic evolution of morphogenic phases for the south-west sector of Nawarla Gabarnmang, also showing location of excavation Square A (see Figure 7 for legend).

(C) Antiquity Publications Ltd. 
smaller, movable pieces; blocks that were too large to break were trimmed along their edges; and blocks of all but the largest size were removed to the edges of the site.

\section{Stone structures}

Archaeomorphological mapping of the shelter floor has also revealed a number of anthropogenic structures. These are characterised by the oblique stacking of three to

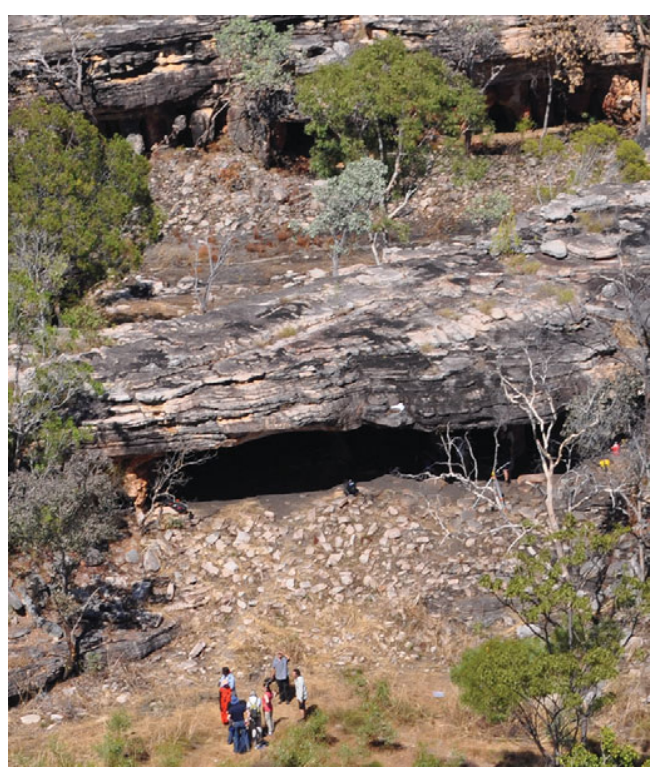

Figure 11. Northern entrance of Nawarla Gabarnmang, showing anthropogenically accumulated quartzite slabs of regular size and shape on talus slope (C)Bruno David and the Jawoyn Association).

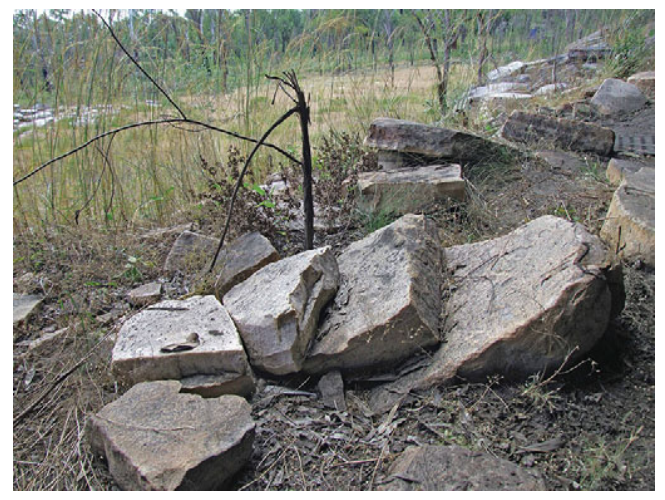

Figure 12. Stacked slabs, Nawarla Gabarnmang. The slabs were stacked as scaffolding to access the ceiling of the cave to permit quarrying and/or painting (C)Jean-Jacques Delannoy and the Jawoyn Association).

(C) Antiquity Publications Ltd. four slabs of relatively standardised size and thickness $(0.4 \mathrm{~m}$ long $\times 0.4 \mathrm{~m}$ wide $\times 0.1 \mathrm{~m}$ high) (Figure 12). Lithostratigraphic analysis reveals that these slabs usually belonged to a single layer from the ceiling, originating from strata that were partially removed in ancient times, but rarely representing the most recent collapsed layer. Finally, these structures are found where the ceiling is most elevated, and where remaining ceiling slabs have been flaked as well as where large painted friezes occur.

Archaeomorphological study allows us to rule out a natural explanation for these structures: how would we explain the superposition of slabs originating from the same ceiling stratum? Examination of the edges of the slabs also reveals impact marks, indicating that their similar sizes are not coincidental. Each block was selected and standardised in size for the building of the stacked structures. Given their locations underneath extensively flaked and painted parts of the ceiling, these structures were likely made to act as stools to reach the overlying ceiling more easily. Was this to enable people to flake the ceiling for the manufacture of stone tools, to paint the vast frescoes on the ceiling, or both? Do the different structures, and the flaked and painted ceiling, date to the same period or are they of different ages? Excavation against and beneath the structures is in progress and will enable these questions to be resolved. Here it is important to note that the archaeological levels typically go down 
to $0.7-0.8 \mathrm{~m}$ depth, while worked slabs from the ceiling have been found only down to $c .0 .5 \mathrm{~m}$ depth. The chronological relationship of the stepped structures to the buried evidence for the removal of layers of quartzite from the ceiling and pillars, and for quarrying activity and painting events, must be investigated. Coupled with the radiocarbon dating of remaining ceiling and pillar surfaces (e.g. through wasp nests), this will enable a historicisation of processes of aménagement, a new dimension in the archaeological investigation of past human activity at Australian sites.

The archaeomorphological study of Nawarla Gabarnmang has revealed key aspects of its history that enable the site to be seen in an entirely new light. The fact that the present shelter cavity is the result of radical human modifications gives the site a cultural dimension not hitherto considered. To the frescoes and buried evidence for human occupation we can now add the systematic human removal of large sections of the bedrock, allowing us to think of the site not simply as having been refurbished through time, but as an anthropogenically created space. The space between the pillars supporting the vast painted ceiling can now be considered natural only in the way that mechanical and chemical forces affect the ancient surfaces through time: they have been configured by intentional design and material engagements, as well as unintentional outcomes of those engagements (e.g. destabilisation of the bedrock). The floor of Nawarla Gabarnmang was itself cleared of debris—as evidenced by the removal of fallen blocks and the aménagement of large, immovable slabs-just as sections of the ceiling and pillars were removed, a clearance presumably designed to make the site more amenable to human occupation. Archaeomorphological investigation allowed us to work at different spatial scales and highlight different forms of aménagement: the creation and expansion of shelter cavities and the formation of rock structures by which artists and stone workers could reach a ceiling that had become too high. Archaeomorphology has offered a new look at the site: it can no longer be understood as the exclusive product of natural processes that seem to betray the basic laws of nature, but a place fashioned by people in the depths of time.

\section{Conclusion}

This paper is intended to introduce the concept of archaeomorphology as a new approach to archaeological sites. Complementary to and employing the same individual techniques as more conventional archaeological and geomorphological approaches, archaeomorphology allows us to identify anthropogenic engagements with the materiality of a place in the morphogenesis of sites. It helps us address the degree to which features within archaeological sites were caused by dwelling and inhabitation (e.g. Ingold 1993; Thomas 2008). Archaeomorphology is based on the same principles shared by both parent disciplines of geomorphology and archaeology: to define the morphogenic processes responsible for end-states by detailing each phase in a relative or absolute chronology. The means by which this can be realised is through mapping, whereby the spatial distribution of objects within a site can be investigated and their origins questioned. Archaeomorphology aims to foreground the role of people in the aménagement of sites and establish a chronology of human interventions. 
The two culturally unrelated examples considered here, Chauvet Cave and Nawarla Gabarnmang, elucidate processes by which sites came to be configured in their final states. These two sites are exceptional for their age, their integrity and their physical state; but they are not exceptional when it comes to the dwelling perspective at the heart of aménagement, social geomorphology and archaeomorphology. They emphasise the important role played by people in the spatial organisation of sites, and enable us to overturn assumptions that these were natural settings into which people entered. Instead, we can come to know those same spaces not as passive stages for human use or occupation, but as actively constructed social spaces. The materiality of a cave or rockshelter is understood to be social fabric: its location, layout, texture, temperature, dryness and size are socially imbued with meaning. Put simply, sites become socially meaningful materiality. At Chauvet Cave, archaeomorphology has enabled us to identify actively constructed social locales in the midst of deep, dark, 'hidden' and liminal cave spaces. We are able to consider the cave not just as a place where paintings were made across expansive walls (for whatever reasons), but one where social activity revolved around constructed features. Similarly, archaeomorphology has revealed Nawarla Gabarnmang to be not so much a generalised 'occupation site' as an actively hollowed industrial and symbolic space. Through their engagement, people configured space in acts of structuration (Giddens 1984) that were no less significant than a continuously engaged, weathering, and reworked architectural design.

\section{Acknowledgements}

We thank the Jawoyn Association Aboriginal Corporation for their invitation to undertake this research, and dedicate this paper to the late Bilginna Ranch. Warm thanks to Élisa Boche, Stéphane Jaillet, Lara Lamb, Jacqueline Matthews, Magen O'Farrell, Benjamin Sadier, Chris Urwin and Brit Wilson for fieldwork; the Ministère de la Culture (France), Monash University, the Department of Sustainability, Environment, Water, Population and Communities (SEWPaC) Indigenous Heritage Program, the Australian Research Council Discovery Grant and QEII Fellowship (to BD) DPDP0877782 and Linkage Grant LP110200927, and the EDYTEM laboratories of the Université de Savoie (France) for continued support and funding. Thanks to an anonymous referee, Jane Balme and Chris Scarre for useful comments on an earlier draft.

\section{References}

BURNS, J.A. 2005. What about behavior? Methodological implications for rockshelter excavation and spatial analysis. North American Archaeologist 26: 267-82.

Carson, L.J., P.W. Haines, A. Brakel, B.A. Pietsch \& P.A. FERENCZI. 1999. Milingimbi SD53-2, 1:250 000 geological map series explanatory notes. Darwin: Northern Territory Geological Survey.

CASEY, E. 1993. Getting back into place: toward a renewed understanding of the place-world. Bloomington: Indiana University Press.

Clottes, J. (ed.) 2001. La grotte Chauvet: l'art des origines. Paris: Le Seuil.

(C) Antiquity Publications Ltd.
David, B., J.-M. Geneste, R.L. WheAR, J.-J. Delannoy, M. Katherine, R.G. Gunn, C. Clarkson, H. Plisson, P. Lee, F. Petchey, C. Rowe, B. Barker, L. Lamb, W. Miller, S. Hoerlé, D. James, E. Boche, K. Aplin, I.J. McNiven, T. Richards, A. Fairbairn \& J. MATTHEWs. 2011. Nawarla Gabarnmang, a 45,180 $\pm 910 \mathrm{cal}$ BP site in Jawoyn country, south-west Arnhem Land plateau. Australian Archaeology 73: 73-77.

Delannoy, J.-J., E. Debard, C. Ferrier, B. Kervazo \& Y. PerretTe. 2001. Contribution de la cartographie morphologique souterraine dans l'étude spéléogénique de la grotte Chauvet: implications paléogéographiques, préhistoriques et paléontologiques. Quaternaire 12: 235-48. 


\section{Jean-Jacques Delannoy et al.}

Delannoy J.-J., Y. Perrette, E. Debard, C. Ferrier, B. Kervazo, A.S. Perroux, S. Jaillet \& Y. QUINIF. 2004. Intérêt de l'approche morphogénique pour la compréhension globale d'une grotte à haute valeur patrimoniale: la grotte Chauvet (France). Karstologia 44: 25-42.

Delannoy J.-J., J.-M. Geneste, S. Jaillet, E. Boche \& B. SADIER. 2012. Les aménagements et structures anthropiques de la grotte Chauvet-Pont-d'Arc (France): apports d'une approche intégrative géomorpho-archéologique. Collection EDYTEM 13 43-62.

Geneste, J.-M., B. David, H. Plisson, J.-J. Delannoy \& F. Petchey. 2012. The origins of ground-edge axes: new findings from Nawarla Gabarnmang, Arnhem Land (Australia) and global implications for the evolution of fully modern humans. Cambridge Archaeological Journal 22: 1-17.

Genty, D., B. Ghaleb, V. Plagnes, C. Causse, H. Valladas, D. Blamart, M. Massault, J.-M. Geneste \& J. ClotTes. 2004. Datations U/Th (TIMS) et 14C (AMS) des stalagmites de la grotte Chauvet (Ardèche, France): intérêt pour la chronologie des événements naturels et anthropiques de la grotte. Comptes Rendus Palevol 3 : 629-42.

GIDDENS, A. 1984. The constitution of society: outline of the theory of structuration. Berkeley: University of California Press.

HEYDARI, S. 2007. The impact of geology and geomorphology on cave and rockshelter archaeological site formation, preservation and distribution in the Zagros Mountains of Iran. Geoarchaeology 22: 653-69.

HugHes, P.J. 1977. A geomorphological interpretation of selected archaeological sites in southern coastal New South Wales. Unpublished PhD dissertation, University of New South Wales.
INGOLD, T. 1993. The temporality of the landscape. World Archaeology 25: 152-74.

- 2000. The perception of the environment: essays on livelihood, dwelling and skill. London: Routledge.

Joly, F. 1977. Point de vue sur la géomorphologie. Annales de Géographie 86: 522-41.

Leroi-Gourhan, A. 1965. Préhistoire de l'art occidental. Paris: Mazenod.

LORBLANCHET, M. 2010. Art pariétal: grottes ornées du Quercy. Rodez: Éditions du Rouergue.

QUINIF, Y. 2010. Fantômes de roche et fantômisation. Essai sur un nouveau paradigme de karstogénèse (Karstologia Mémoires 18). Mons: Y. Quinif.

SCHIFFER, M.B. 1976. Behavioral archeology. New York: Academic.

Theunissen, R., J. BALME \& W. BeCK. 1998. Headroom and human trampling: cave ceiling-height determines the spatial patterning of stone artefacts at Petzkes Cave, northern New South Wales. Antiquity 72: 80-89.

Thomas, J. 2008. Archaeology, landscape, and dwelling, in B. David \& J. Thomas (ed.) Handbook of landscape archaeology: 300-306. Walnut Creek (CA): Left Coast.

Tilley, C. 1994. A phenomenology of landscape: places, paths and monuments. Oxford: Berg.

TuAN, Y.-F. 1977. Space and place: the perspective of experience. Minneapolis: University of Minnesota Press.

Valladas, H. \& J. Clottes. 2003. Style, Chauvet and radiocarbon. Antiquity 77: 142-45.

VAN DyKe, R.M. 2008. The Chaco experience: landscape and ideology at the center place. Santa Fe (NM): School of Advanced Research Press.

Received: 18 June 2012; Accepted: 28 September 2012; Revised: 5 October 2012

(C) Antiquity Publications Ltd. 